\title{
Fourier transform infrared (FT-IR) spectra characterization of recycled carbon fiber composites: Mini review
}

\author{
${ }^{1,2}$ Azadeh Tavousi Tabatabaei, ${ }^{11}$ Seyed Hossein Mamanpush and ${ }^{3}$ Bahareh Tavousi Tabatabaei \\ ${ }^{1}$ Composite Materials and Engineering Center, Washington State University, Pullman, WA, \\ 99163, USA \\ ${ }^{2}$ Department of Chemistry, Shahid Beheshti University, Tehran, Iran. \\ ${ }^{3}$ Department of Engineering, Islamic Azad University, Khomeyni Shahr Branch, Isfahan, Iran.
}

\begin{abstract}
Post-industrial off-cuts of carbon fiber epoxy and carbon fiber vinyl ester composites recycled mechanically and characterized by Fourier transform infrared (FT-IR) to obtain an infrared spectrum of absorption or emission of the untreated and heat-treated recycled carbon fiber composites. FT-IR spectra were recorded with a Bomem MB series FT-IR spectrophotometer.
\end{abstract}

\section{FTIR characterization}

The use of carbon fiber composites (CFCs) is dramatically increasing due to their higher fatigue life, better corrosion and fire resistance, and more flexible design options over conventional materials. The process from manufacturing carbon fiber to production of finished components is wasteful; it is estimated that more than $30 \%$ of produced carbon fiber ends up as waste at some point in the process. Unlike their metal counterparts, wastes produced during synthetic-fiber composites (SFCs) manufacturing and assembly, along with end-of-life products, have limited options for reuse. [1-3]. Options to incinerate or disposal has negative environmental contributions and disregards the potential recycled CFCs have as a feedstock for second generation products. There is a potential to recycle the carbon fiber from the thermoset matrix via chemical or thermal treatments, however the resulting fiber is often lower in mechanical properties than virgin fibers and are very difficult to disperse into many matrices due to their crimped and entangled form. Mechanical techniques that employ shredders, hammer-mills, knife-mills, etc. provide a low-cost option to deliver a reliable feedstock. Mechanical recycling is a low-cost and energy-efficient method for CFCs [4-6].

FT-IR spectra of untreated and heat-treated mechanically recycled carbon fiber epoxy and carbon fiber vinyl ester composites (CFC) are shown in Figures 1 to 4 respectively. The spectra of epoxybased CFC show a band at $1507 \mathrm{~cm}^{-1}$, corresponding to $\mathrm{C}-\mathrm{H}$ bending and a band at $1734 \mathrm{~cm}^{-1}$ assigned to the $\mathrm{C}=\mathrm{O}[3-4]$. The FT-IR spectrum of vinyl ester-based $\mathrm{CFC}$ exhibits a band at 1716 $\mathrm{cm}^{-1}$ corresponding to the $\mathrm{C}=\mathrm{O}$ and a band at $1540 \mathrm{~cm}^{-1}[7-9]$

\footnotetext{
${ }^{1}$ Corresponding Author
} 


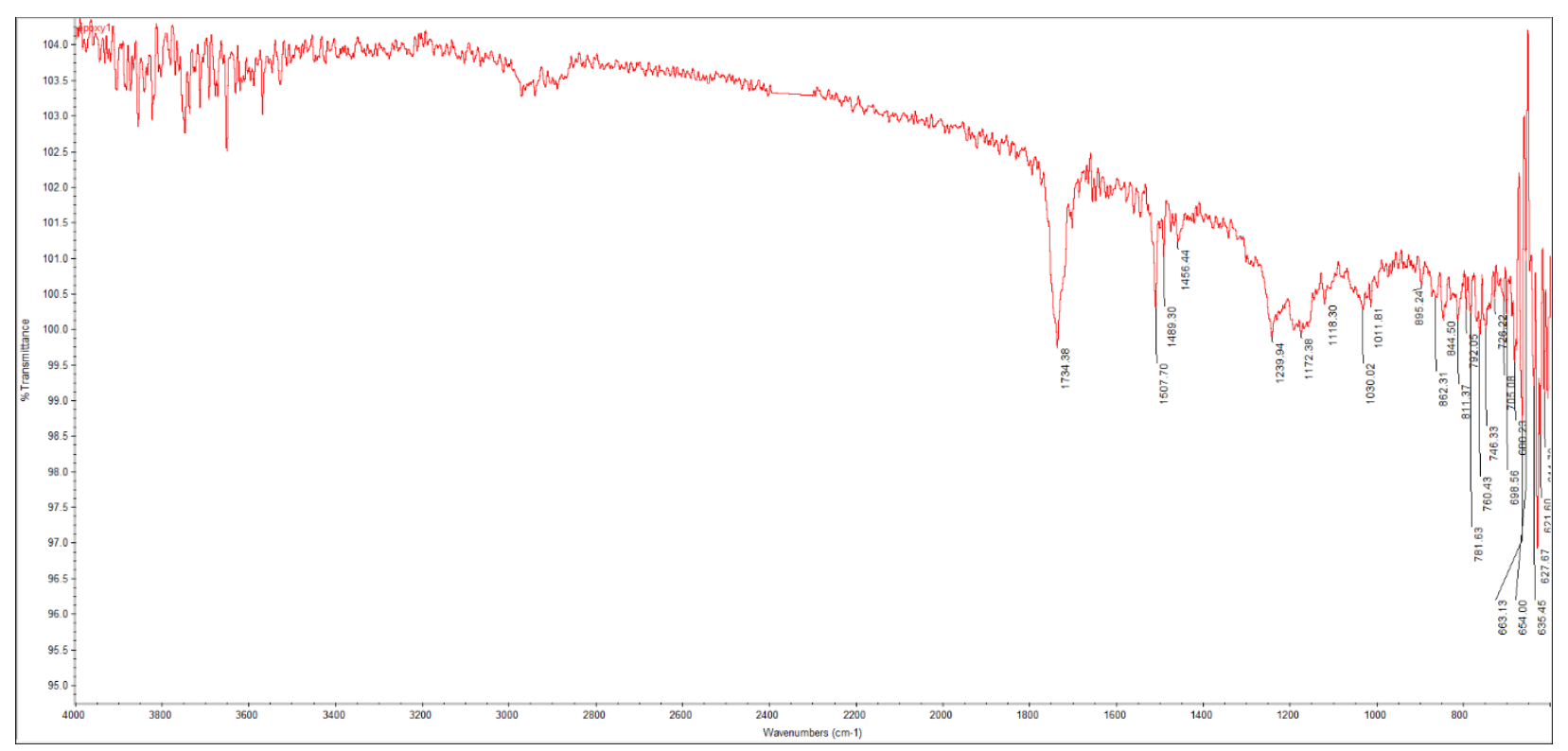

Figure 1. FT-IR spectra of epoxy-based CFC.

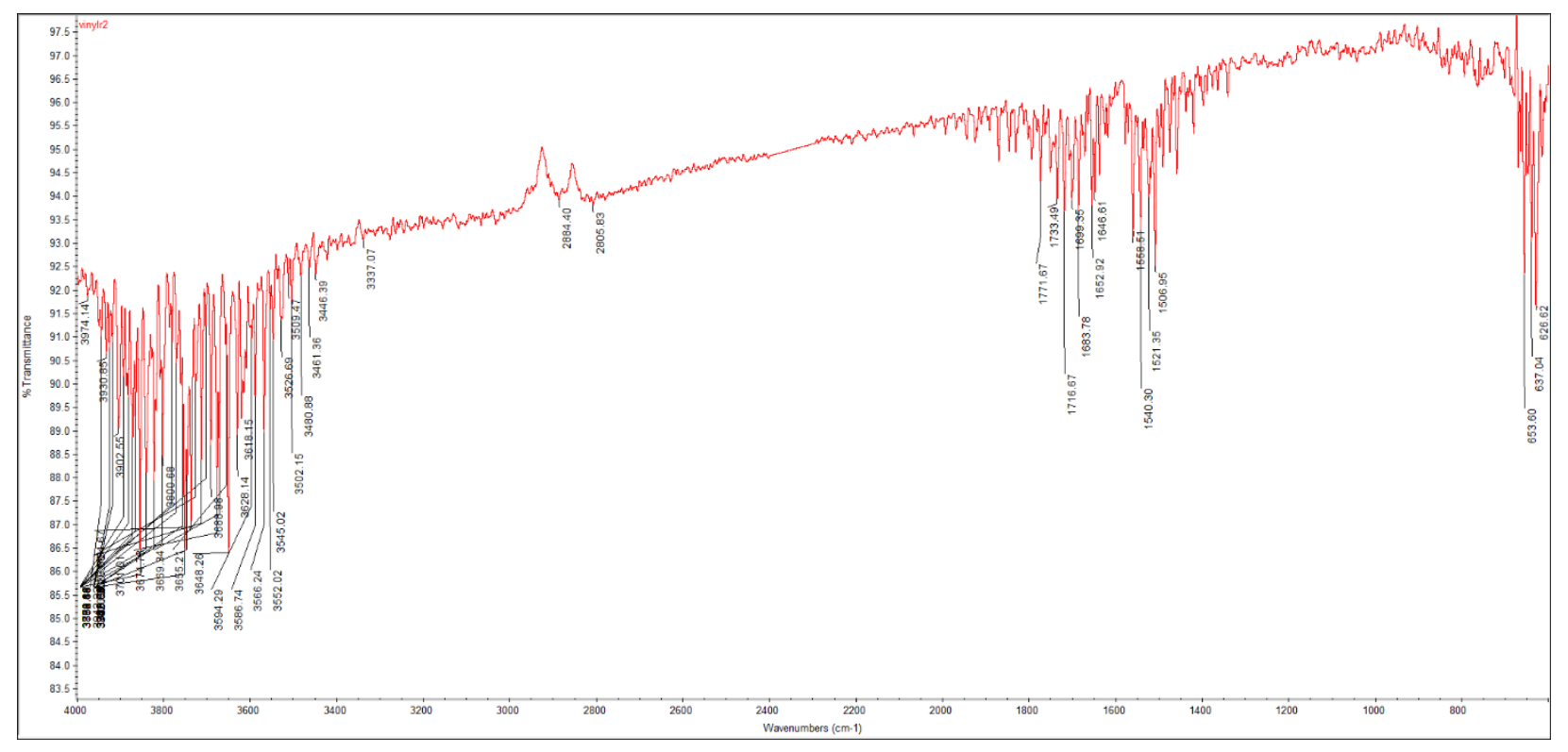

Figure 2. FT-IR spectra of Vinyl ester-based CFC.

Comparing FT-IR of untreated and heat treated rCFC indicates that there is no significant difference between their spectra. 


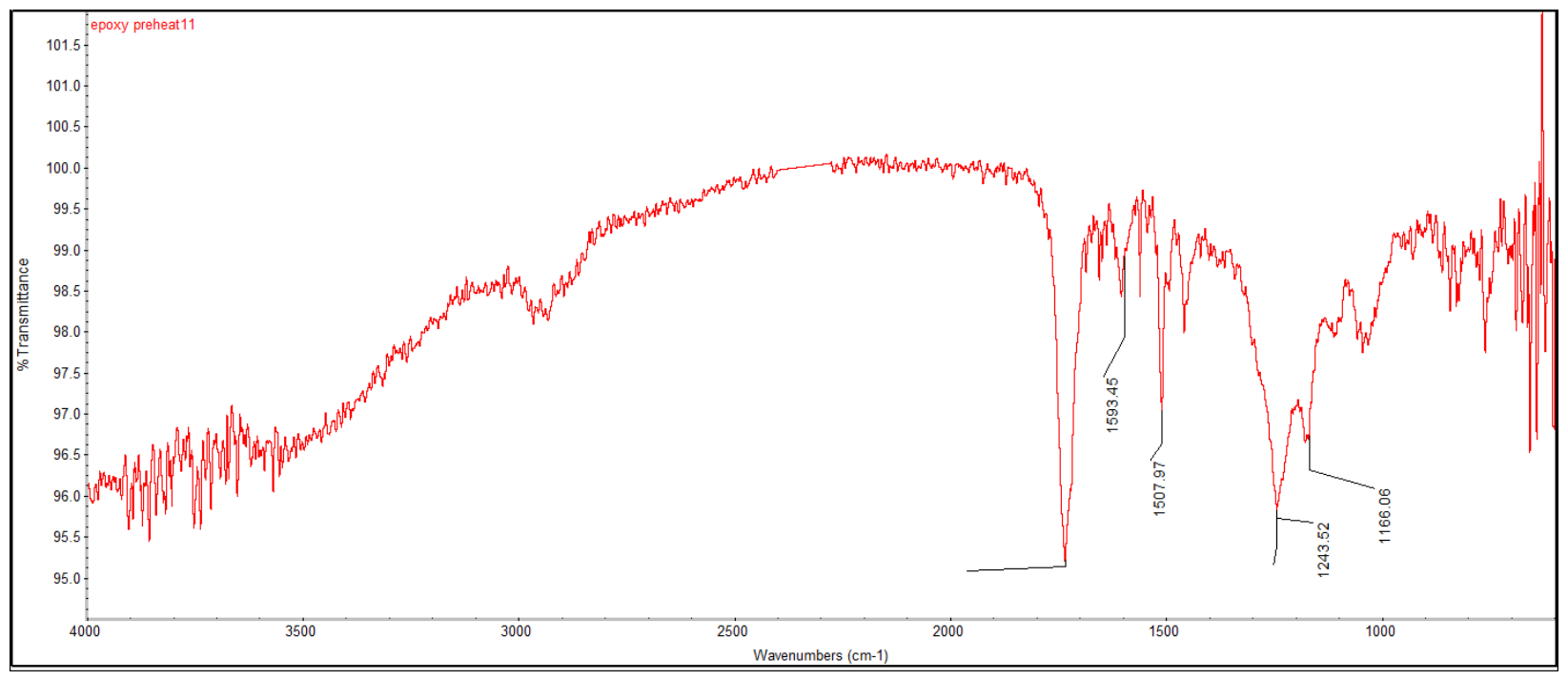

Figure 3. FT-IR spectra of heat-treated epoxy-based CFC.

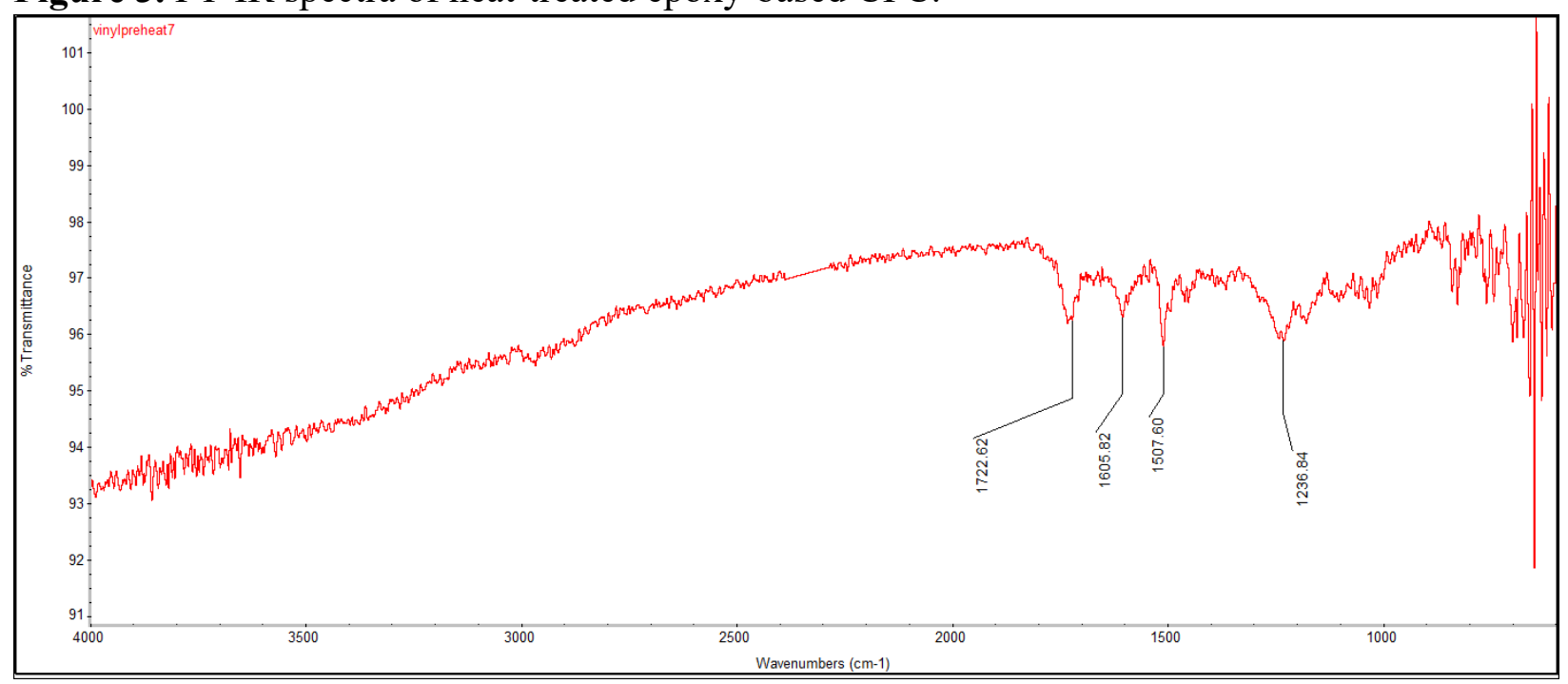

Figure 4. FT-IR spectra of heat-treated Vinyl ester-based CFC

\section{References:}

[1] Mamanpush H, Golestanian H, Investigating the Effects of Carbon Nanotube Orientation on the Macroscopic Stiffness of Nanocomposites, international Journal of Current Life Sciences, Vol.4, Issue 4, pp.1168-1174, April 2014.

https://www.researchgate.net/publication/313860245 Investigating the Effects of Carbon Nanotube Orie ntation on the Macroscopic Stiffness of Nanocomposites

[2] Mamanpush H, Golestanian H, Evaluation of Effective Material Properties of Randomly Distributed Carbon Nanotube Composites Considering Interface Effect, Indian Journal of Scientific Research 2(1):132-142. 
https://www.researchgate.net/publication/313860249_Evaluation_of_Effective_Material_Properties_of_Rand omly_Distributed Carbon_Nanotube_Composites_Considering_Interface_Effect

[3] Mamanpush H, Golestanian H, Effects of Carbon Nanotube Dispersion on the Mechanical Properties of Nanocomposites Considering Interface Effect, International Journal of Current Research 4(8):4366-4373. https://www.researchgate.net/publication/313860143 "Effects of Carbon Nanotube Dispersion on the Me chanical Properties of Nanocomposites Considering Interface Effect

[4] Ahmad Shaabani, Seyyed Emad Hooshmand, Azadeh Tavousi Tabatabaei; Synthesis of fully substituted naphthyridines: a novel domino four-component reaction in a deep eutectic solvent system based on choline chloride/urea, Tetrahedron Letters, Vol.57 (3) pp. 351-353. https://doi.org/10.1016/i.tetlet.2015.12.017

[5] Ahmad Shaabani, Ronak Afshari, Seyyed Emad Hooshmand, Azadeh Tavousi Tabatabaei, Fatemeh Hajishaabanha, Copper supported on MWCNT-guanidine acetic acid@Fe304: synthesis, characterization and application as a novel multi-task nanocatalyst for preparation of triazoles and bis(indolyl)methanes in water, RSC Adv., 2016, 6, 18113-18125.

https://doi.org/10.1039/C5RA23294E

[6] Seyed Hossein Mamanpush, Hui Li, Karl Englund, Azadeh Tavousi Tabatabaei, Recycled wind turbine blades as a feedstock for second generation composites, Waste Management,2018, 76, 708-714. https://doi.org/10.1016/j.wasman.2018.02.050

[7] Shabnam Shaabani, Azadeh Tavousi Tabatabaei, Ahmad Shaabani, Copper(I) oxide nanoparticles supported on magnetic casein as a bio-supported and magnetically recoverable catalyst for aqueous click chemistry synthesis of 1,4-disubstituted 1,2,3-triazoles, Applied Organometallic Chemistry, 31 (2). https://doi.org/10.1002/aoc.3559

[8] Seyed Hossein Mamanpush, Azadeh Tavousi Tabatabaei, Hui Li, Karl Englund, "Data on the mechanical properties of recycled wind turbine blade composites", Data in Brief, Volume 19, August 2018, Pages 230-235. https://doi.org/10.1016/i.dib.2018.05.008

[9] Seyed Hossein Mamanpush, Hui Li, Karl Englund, Azadeh Tavousi Tabatabaei, "Dataset demonstrating physical properties of recycled wind turbine blade composites", Data inBrief 20 (2018) 658-661. https://doi.org/10.1016/j.dib.2018.08.123 